\title{
Prostat Biyopsisi Öyküsü Olan Hastalarda Transrektal Ultrason Kılavuzluğunda Yapılan Prostat Rebiyopsisi Sırasında Ağrı Skorları Değiş̧iyor mu?
}

\section{Do the Pain Scores During Transrectal Ultrasound-guided Prostate Rebiopsy Change in Patients with a Prior History of Prostate Biopsy?}

\author{
Dr. Deniz Bolat, Dr. Mehmet Erhan Aydın, Dr. Bülent Günlüsoy, Dr. Tansu Değirmenci, Dr. Yusuf Kadir Topçu, \\ Dr. İbrahim Küçüktürkmen, Dr. Zafer Kozacıoğlu
}

Bozyaka Eğitim ve Araștırma Hastanesi, Üroloji Kliniği, lzmir, Türkiye

Öz

Amaç: Bu çalışmada prostat biyopsisi öyküsünün, transrektal ultrason kılavuzluğunda prostat biyopsisi (TRUS-PBx) yapılan hastalardaki ağrı üzerine etkisini değerlendirdik.

Gereç ve Yöntem: Ekim 2014 ve Nisan 2015 tarihleri arasında, anormal dijital rektal muayene bulgusu, yüksek prostat spesifik antijen (PSA) değeri $(\geq 2,5 \mathrm{ng} / \mathrm{mL})$ ya da önceki biyopsilerinde prostat kanseri açısından şüpheli lezyonlar nedeniyle ilk kez ya da tekrar biyopsi yapılacak 198 hasta çalışmaya dahil edildi. Biyopsiden önce tüm hastalara $10 \mathrm{~mL} \% 2$ prilokain ile transperineal periprostatik blok uygulandı. 10'luk vizüel analog skala (VAS) prob girişi esnasındaki (VAS-1) ve prostat örneklemesi esnasındaki (VAS-2) ağrıları değerlendirmak için kullanıldı. Hastalar iki gruba ayrıldı: Prostat biyopsisi öyküsü olmayanlar grup 1'e, olanlar grup 2'ye dahil edildiler.

Bulgular: Hastaların ortalama yaşı $64 \pm 7,3$ yıl, ortalama PSA değeri $12,5 \pm 18,3 \mathrm{ng} / \mathrm{dL}$ idi. Prostat kanseri tespit oranı \%22,7 idi. Grup 1 'de 173, grup 2'de 25 hasta vardı. VAS-1 skorları gruplar arasında karşılaştııılabilir düzeydeydi $(1,7 \pm 2,0$ 'a $1,7 \pm 1,8 ; p=0,957)$. VAS-2 skoru grup $2^{\prime}$ de grup $1^{\prime}$ den daha düşük olmakla birlikte $(2,0 \pm 2,3$ 'e $2,6 \pm 2,4)$, aradaki fark istatistiksel açıdan anlamlı değildi $(p=0,290)$.

Sonuç: Önceki prostat biyopsisi deneyimi TRUS-PBx sırasındaki ağrı skorlarını etkilememektedir.

Anahtar Kelimeler: Prostat kanseri, prostat biyopsisi, lokal anestezi, ağrı, rebiyopsi

\begin{abstract}
Objective: In this study we evaluated the effects of prior history of prostate biopsy on pain scores of patients who underwent transrectal ultrasound-guided prostate biopsy (TRUS-PBx).

Materials and Methods: Between October 2014 and April 2015, 198 patients who underwent primary or repeat prostate biopsy with abnormal digital rectal examination findings, high prostate specific antigen (PSA) levels $(\geq 2.5 \mathrm{ng} / \mathrm{mL}$ ) or suspicious lesions for prostate cancer in prior biopsies were included in the study. Before the biopsy procedure, all patients underwent transperineal periprostatic block with $10 \mathrm{~mL}$ of $2 \%$ prilocaine. A 10 -point linear visual analogue scale (VAS) was used to assess the pain arising from probe insertion (VAS-1) and prostate sampling (VAS-2). Patients were separated into two groups: Patients without a prior prostate biopsy were enrolled in group 1 and the patients with history of prostate biopsy were enrolled in group 2.

Results: The mean age of the patients was $64 \pm 7.3$ years, and the mean PSA value was $12.5 \pm 18.3 \mathrm{ng} / \mathrm{dL}$. Prostate cancer detection rate was $22.7 \%$. There were 173 patients in group 1 and 25 patients in group 2 .

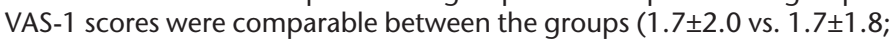
$\mathrm{p}=0.957)$. VAS- 2 score was lower in group 2 than group 1 's $(2.0 \pm 2.3$ vs. 2.6 2.4 ); however, the difference was not statistically significant $(\mathrm{p}=0.290)$.

Conclusion: Prior prostate biopsy experience does not affect the pain scores during TRUS-PBX.

Keywords: Prostate cancer, prostate biopsy, local anesthesia, pain, rebiopsy
\end{abstract}

Yazışma Adresi/Address for Correspondence: Dr. Deniz Bolat, Bozyaka Eğitim ve Araştırma Hastanesi, Üroloji Kliniği, İzmir, Türkiye Tel.: +90 5056383010 E-mail: drbolat@hotmail.com Geliş Tarihi/Received: 28.11.2016 Kabul Tarihi/Accepted: 29.12.2016 


\section{Giriş}

Prostat kanseri, Amerika Birleşik Devletleri'nde yaşayan erkeklerde en sık görülen malignite tipidir. İstatistiklere göre, 2016 yılında yaklaşık 180,890 Amerikalı erkeğe prostat kanseri tanısı konulması ve 26,120 erkeğin bu hastalıktan dolayı ölmesi beklenmektedir (1). Transrektal ultrason kılavuzluğunda yapılan prostat biyopsisi (TRUS-PBx) prostat kanserinin tanısında günümüzdeki altın standart yöntemdir. Hastalardan bazıları bu işlemi rahatlıkla tolere edebilirken, bazıları çok ciddi ağrı ve rahatsızlık duymaktadırlar (2). Irani ve ark.'nın (3) çalışmasında, herhangi bir anestezi uygulanmayan hastaların çoğu TRUSPBx işlemini yalnızca hafif derecede rahatsızlık verici olarak belirtirlerken, \%19'u herhangi bir anestezi uygulanmadığı takdirde aynı işlemi bir daha yaptırmayacaklarını bildirmişlerdir. Bir başka çalışmada ise işlemden önce intrarektal lidokain uygulaması yapılsa bile hastaların \%50'sinin orta-dayanılmaz şiddette ağrı duydukları gösterilmiştir (4). Bu nedenle, TRUS-PBx işleminden önce ağrı kontrolünün etkili bir şekilde sağlanması gerekmektedir.

Biyopsi işleminden önce, hastayı yapılacak işlemin aşamaları hakkında bilgilendirmek hastanın anksiyetesinin azalmasına katkı sağlamaktadır (5). Günümüzde, prostatı inerve eden nörovasküler demetin Denonvillier fasyası içerisinde direkt anestezisini içeren periprostatik sinir blokajı (PPSB) standart teknik olarak önerilmektedir (6). Bu tekniğe alternatif olarak ileri sürülen transperineal PPSB (TPPSB) ise, özellikle anorektal patolojisi olan hastalarda uygulanabilecek güvenli ve etkili bir yöntemdir (7).

Yapılan bazı çalışmalarda TRUS-PBx'ten önce uygulanan anestezi tekniğinin her hastada aynı etkiyi göstermediğini, bazı hastaların kombine yöntemlere ihtiyaç duyduğu gösterilmiştir (8). Buradan hareketle biyopsi sırasında hissedilen ağrıya etki edebilecek faktörler inceleme konusu olmuştur. Yapılan çalışmalarda hasta yaşının, biyopside alınan kor sayısının ve lokalizasyonunun, prostat hacminin ve işlem sırasındaki hasta pozisyonunun TRUS-PBx sırasında hissedilen ağrı üzerine olan etkileri değerlendirilmiştir $(9,10,11)$. Biz bu çalışmada, prostat biyopsisi öyküsü olan hastaların tekrarlayan biyopsilerdeki ağrı düzeylerini ilk kez biyopsi uygulanacak olan hastalarla karşılaştırarak, biyopsi öyküsünün ağrı parametreleri üzerine etkisini araştırdık.

\section{Gereç ve Yöntem}

Ekim 2014 ile Nisan 2015 tarihleri arasında kliniğimizde prostat spesifik antijen (PSA) yüksekliği ( $\geq 2,5 \mathrm{ng} / \mathrm{mL}$ ) olması, parmakla rektal incelemede prostatında şüpheli lezyon tespit edilmesi, önceki biyopsilerinde şüpheli lezyon (çok odaklı prostatik intraepitelyal neoplazm, atipik küçük asiner proliferasyon) olması üzerine ilk kez ya da tekrar TRUS-PBx yapılan toplam 198 hasta çalışmaya dahil edildi. İlk kez biyopsi yapılan hastalar grup 1'e, tekrar biyopsi yapılanlar ise grup 2'ye dahil edildiler.

Bu çalışma Bozyaka Eğitim ve Araştırma Hastanesi Etik Kurulu'nun 10.03.2015 tarih ve 01 no'lu kararıyla onaylandı ve çalışmaya katılan hastalardan bilgilendirilmiş gönüllü onam formu alındı. Hastalara işlemden önce ve işlem sonrası 3 gün kullanmak üzere florokinolon profilaksisi verildi ve barsak temizliği olarak işlem günü rektal lavman uygulandı. Tüm hastalara biyopsi öncesinde $10 \mathrm{~mL}$ \%2 prilokainle parmak kılavuzluğunda TPPSB uygulandı (7).
Tekrar biyopsi işlemi, persistan yüksek PSA'sı olan, ilk biyopsisi negatif olmasına rağmen şüpheli rektal muayene bulgusu olan, ilk biyopsi patoloji raporu multifokal yüksek dereceli prostatik intraepitelyal neoplazi ya da atipik küçük asiner proliferasyon (ASAP) olarak gelen hastalara uygulandı.

Anestezi tekniği: Hastaya dorsal litotomi pozisyonu verildikten sonra perineal cilt antiseptik solüsyon kullanılarak temizlendi. Hastaya skrotumu perinenin üzerinde olacak şekilde kaldırtıldı. Operatörün eldivenli sol işaret parmağı anal kanala yerleştirildi. Bu parmak kılavuzluğunda, 27 G iğneyle orta hattan 300 açıyla rektumun yaklaşık 1,5-2,0 cm üzerinden, sağ tarafta transperineal cilt ve cilt altı dokular sağ prostatik lob tabanına kadar geçildi. İntravasküler enjeksiyon önlemek için, enjektör aspire edildi. Aspirasyonal kan gelmediği gözlendikten sonra, iğne prostatın tabanından apeksine doğru geri çekilirken $5 \mathrm{~mL}$ anestezik ajan enjekte edildi. Enjekte edilen ajan, anal kanalda işaret parmağı ucuyla prostat yüzeyinde şişlik olarak hissedildi. Aynı işlem, iğne perineal ciltten çıkarılmaksızın, sol taraf için de uygulandı (7).

Biyopsi tekniği: TRUS, ürolog tarafından BK Medical Flex Focus ultrason tarayıcıya bağlanmış çok düzlemli çok frekanslı prob ile gerçekleştirildi. Biyopsi öncesinde prostat hacmi prostat elipsoid formülü ile hesaplandı. Örnekleme, anestezik ajan enjeksiyonundan beş dakika sonra başlatıldı. Biyopsi işlemi 18 G Trucut ${ }^{\mathrm{TM}}$ iğne ile, ilk kez biyopsi yapılacak olan hastalarda standard 10-12 kor şeklinde uygulanırken, tekrar biyopsi yapılacak olan hastalarda her iki transizyonel zonları ve şüpheli nodülden alınacak biyopsileri de içerecek şekilde en az 16 kor şeklinde otomatik biyopsi tabancası kullanılarak gerçekleştirildi. Ağrı skorları 10'luk lineer vizüel analog skala (VAS) kullanılarak, ultrason probu rektuma yerleştirildikten hemen sonra VAS-1 ve biyopsi esnasında iğne girişi sırasında VAS-2 ağrı düzeyi değerlendirildi. VAS skorunda 0 ağrısız (veya hiç rahatsızlık duymadım) olarak skorlandırılırken, 10 dayanılmaz ağrı (veya dayanılmaz rahatsızlık) olarak belirlendi.

\section{İstatistiksel Analiz}

Veriler Statistical Package for Social Sciences (SPSS, version 17.0 for Windows, Chicago, IL, USA) programı ile analiz edildi ve değişkenin tipine göre ortalama \pm standart sapma, sayı ve yüzde olarak verildi. Íki grup arasında sayısal verilerin karşılaştırılması için bağımsız gruplar t testi, kategorik verilerin karşılaştırılması için ki-kare testi kullanıldı. $\mathrm{P}<0,05$ değerler istatistiksel olarak anlamlı kabul edildi.

\section{Bulgular}

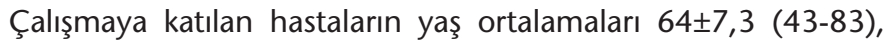
ortalama PSA değerleri 12,5 $\pm 18,3$ (0,6-142) ng/dL idi. Prostat kanseri tespit oranı \%22,7 olarak bulundu (Tablo 1).

Çalışmaya dahil edilen hastaların patoloji sonuçları değerlendirildiğinde; 60'ında $(\% 30,3)$ benign prostat hiperplazisi, 52'sinde (\%26,3) kronik prostatit, 24'ünde (\%12,1) prostatik intraepitelyal neoplazi (PIN), 11'inde $(\% 5,5)$ ASAP, $45^{\prime}$ inde $(\% 22,7)$ prostat adenokarsinomu ve 6 'sında $(\% 3,1)$ PIN + kronik prostatit tespit edildi (Tablo 1).

Çalışmaya dahil edilen hastaların 173'üne ilk kez, 25'ine ise tekrar biyopsi yapılmıştı.

Hastaların VAS-1 ortalamaları karşılaştırıldığında, grup 1'de $1,7 \pm 2,0$ ve grup $2^{\prime}$ de $1,7 \pm 1,8$ idi $(p=0,952)$. VAS-2 değerleri 
ise grup 1 ve 2 için sırasıyla; $2,6 \pm 2,4$ ve $12,0 \pm 2,3$ idi $(p=0,290)$ (Tablo 2).

\section{Tartışma}

TRUS-PBx, kanser tespit olasılığını artırmanın yanı sıra aktif izlem yapılan hastaların takibi nedeniyle yapılan tekrar biyopsi sayısındaki artışa bağlı olarak yaygın olarak uygulanmaktadır (12). Eğer bu işlem herhangi bir analjezi ya da anestezi uygulaması yapılmaksızın gerçekleştirilirse hastalarda ağrıya ve rahatsızlığa neden olmaktadır (3).

Prostat biyopsisi sırasında hissedilen ağrının iki orijini vardır: Ultrason probunun rektuma girişi esnasında anal sfinkterdeki gerilmeye bağı hissedilen ağrı ve biyopsi iğnesinin prostata girişi sırasında hissedilen ağrı (13). Illk kez Nash ve ark. (5) tarafından PPSB altında prostat biyopsisi uygulanmış ve bu hastalarda ağrı skorlarının hiçbir analjezi uygulanmayanlara göre daha düşük olduğu bulunmuştur. Daha sonraki çalışmalarda ise PPSB ile kombine intrarektal jel uygulamasının ağrı kontrolünde PPSB'ye daha üstün olduğu gösterilmiştir (8). Bolat ve ark.'nın (7) transperineal periprostatik blok (TPPB) ile PPSB + rektal jel uygulamalarını karşılaştırdıkları çalışmalarında ise prob girişi esnasındaki ağrının kontrolünde TPPB'nin PPSB + rektal jel uygulamasına kıyasla daha üstün olduğu gösterilmiştir.

Biz bu çalışmamızda tüm biyopsi uygulamalarımızı TPPB altında yaptık. Çalışmamızın sonuçlarına göre, TPPB altında TRUSPBx yapılan hastalarda kanser tespit oranımız \%22,7 olarak bulunmuştur. Her ne kadar bu çalışmada ortalama PSA değeri yüksek olsa da $(12,5 \pm 18,3 \mathrm{ng} / \mathrm{dL})$, kanser tespit oranımızın düşük olmasının sebebinin biyopsi işleminin farklı tecrübelerdeki ürologlar ve patolojik incelemelerin farklı tecrübelerdeki patologlar tarafından yapılıyor olmasından kaynaklandığı düşüncesindeyiz.

\begin{tabular}{|c|c|}
\hline Ortalama yaş (yıl) & $64 \pm 7,3$ \\
\hline Ortalama PSA (ng/dL) & $12,5 \pm 18,3$ \\
\hline Ortalama prostat hacmi (cc) & $57,5 \pm 26,5$ \\
\hline Anormal dijital rektal muayene, n (\%) & $76(38,4)$ \\
\hline Ortalama VKi $\left(\mathrm{kg} / \mathrm{m}^{2}\right)$ & $38,1 \pm 27,1$ \\
\hline $\begin{array}{l}\text { Biyopsi patoloji sonucu, n (\%) } \\
\text { BPH } \\
\text { PK } \\
\text { Kronik prostatit } \\
\text { PIN } \\
\text { PIN + Kronik prostatit } \\
\text { ASAP }\end{array}$ & $\begin{array}{l}60(30,3) \\
45(22,7) \\
52(26,5) \\
24(12,1) \\
6(3,0) \\
11(5,6)\end{array}$ \\
\hline \multicolumn{2}{|c|}{$\begin{array}{l}\text { VKI: Vücut kitle indeksi, PSA: Prostat spesifik antijen, BPH: Benign prostat } \\
\text { hiperplazisi, PK: Prostat kanseri, PIN: Prostatik intraepitelyal neoplazisi, ASAP: } \\
\text { Atipik küçük asiner proliferasyon }\end{array}$} \\
\hline
\end{tabular}

Tablo 2. Vizüel analog skala skor ortalamaları (ortalama \pm standart sapma)

\begin{tabular}{|l|l|l|l|}
\hline & Grup 1 $(\mathbf{n}=\mathbf{1 7 3})$ & Grup 2 $(\mathbf{n}=\mathbf{2 5})$ & $\mathbf{p}$ \\
\hline VAS-1 & $1,7 \pm 2,0$ & $1,7 \pm 1,8$ & 0,957 \\
\hline VAS-2 & $2,6 \pm 2,4$ & $2,0 \pm 2,3$ & 0,290 \\
\hline \multicolumn{4}{|l}{} \\
\hline
\end{tabular}

Kullanılan anestezi tekniğinden bağımsız olarak hangi faktörlerin TRUS-PBx sırasında hissedilen ağrıya etki eden faktörleri bilmek ve bu durumlara özgü önlemler almak hasta konforunun sağlanması açısından önemlidir. Bastide ve ark. (14) hiçbir anestezi yöntemi uygulamadan yaptıkları TRUS-PBx sırasında hissedilen ağrıya etki eden faktörlerin araştıııldığı çalışmalarda hasta yaşını, prostat volümün, alınan kor sayısını, operatörü, önceki biyopsi öyküsünü ve alınan ilk kor lokalizasyonunu (apeks ya da basis) değerlendirmişlerdir. Bu çalışmanın sonuçlarına göre hem tekli hem de çoklu analizlerde, sadece alınan ilk kor lokalizasyonunun ağrı ile ilişkili olduğu bulunmuş ve biyopsiye bazisten başlanması gerektiği vurgulanmıştır. Fakat, daha önceki biyopsi öyküsü ile ağrı skorları arasında anlamlı ilişki bulunamamıştır (14). Djavan ve ark.'nın (9) çalışmasında, ilk ve tekrar TRUS-PBx yapılan hastaların ağrı skorlarının ve hasta konforlarının benzer olduğu belirtilmiştir. Bizim çalışmamızda ise, TPPB altında TRUS-PBx uygulanan hastalarda önceki biyopsi öyküsü ile hem prob girişi hem de örnekleme sırasındaki ağrı skorları arasında anlamlı ilişki bulunmamıştır. Bunun nedeni tekrar biyopsi uygulanan gruptaki hasta sayısının yetersiz olması, dolayısıyla gruplar arasındaki hasta sayısı dengesizliği olabilir. Bizim çalışmamı Bastide ve ark. (14) ile Djavan ve ark.'nın (9) bulgularını destekler nitelikte olmakla birlikte Gómez-Gómez ve ark.'nın (15) çalışmasını desteklememektedir. Çünkü GómezGómez ve ark.'nın (15) çalışmasına göre, daha önceden yapılmış biyopsi öyküsü varlığı TRUS-PBx sırasındaki ağrı için bağımsız bir risk faktörüdür.

Prostat biyopsisi sırasındaki ağrıya etki eden faktörlerin araştıııldığı diğer çalışmalarda ise Moussa ve ark. (16) transrektal prob dizaynının ve iğne kılavuzunun TRUS-PBx işleminin her etabında ağrı üzerine etkili olduğunu göstermişlerdir. Bolat ve ark.'nın (17) yaptıkları çalı̧̧malarda ise işlem sırasında hissedilen ağrı ile biyopsi patoloji sonucu arasında ilişki olmadığı gösterilmiştir. Bolat ve ark.'nın (18) beden kitle indeksi (BKI) ile prostat biyopsisi sırasındaki ağrı skorları arasındaki ilişkiyi araştırdıkları bir başka çalışmalarında ise prob girişi esnasında hissedilen ağrı $\mathrm{BKI}<30 \mathrm{~kg} / \mathrm{m}^{2}$ olan hastalarda diğerlerine kıyasla benzer düzeyde bulunurken, örnekleme sırasında hissedilen ağı BKi $<30 \mathrm{~kg} / \mathrm{m}^{2}$ olan hastalarda anlamlı olarak daha yüksek bulunmuştur.

\section{Sonuç}

TRUS-PBX yapılacak olan hastalarda daha önceden prostat biyopsisi öyküsünün bulunması ağıı skorlarını etkilememektedir. TPPB tekrar biyopsi yapılacak hastalarda etkili bir lokal anestezi yöntemidir. Bu hastalarda TRUS-PBx işslemi sırasında ağrıyı azaltmak ve hasta konforunu artırmak için fazladan önlemler almaya gerek yoktur. Fakat bu çalışmanın sonuçları, daha fazla sayıda tekrar biyopsi yapılan hastaların içerildiği geniş kapsamlı prospektif, kontrollü çalışmalarla desteklenmelidir.

\section{Etik}

Etik Kurulu Onayı: Bozyaka Eğitim ve Araştırma Hastanesi Etik Kurulu'nun 10.03.2015 tarih ve 01 no'lu kararılyla onaylanmıştır, 
Hasta Onayı: Hastalardan bilgilendirilmiş onam formu alınmıştır. Hakem Değerlendirmesi: Editörler kurulu ve editörler kurulu dışında olan kişiler tarafından değerlendirilmiş̧tir.

\section{Yazarlık Katkıları}

Cerrahi ve Medikal Uygulama: Mehmet Erhan Aydın, Yusuf Kadir Topçu, Ibrahim Küçüktürkmen, Konsept: Deniz Bolat, Bülent Günlüsoy, Dizayn: Deniz Bolat, Zafer Kozacıoğlu, Veri Toplama veya İşleme: Yusuf Kadir Topçu, Analiz veya Yorumlama: Deniz Bolat, Tansu Değirmenci, Literatür Arama: Ibrahim Küçüktürkmen, Yazan: Mehmet Erhan Aydın, Deniz Bolat. Çıkar Çatışması: Yazarlar bu makale ile ilgili olarak herhangi bir çıkar çatışması bildirmemiştir.

Finansal Destek: Çalışmamız için hiçbir kurum ya da kişiden finansal destek alınmamışır.

\section{Kaynaklar}

1. Siegel RL, Miller KD, Jemal A. Cancer statistics, 2016. CA Cancer J Clin 2016;66:7-30.

2. Wang J, Wang L, Du Y, et al. Addition of intrarectal local analgesia to periprostatic nerve block improves pain control for transrectal ultrasonography-guided prostate biopsy: a systematic review and meta-analysis. Int J Urol 2015;22:62-68.

3. Irani J, Fournier F, Bon D, et al. Patient tolerance of transrectal ultrasound-guided biopsy of the prostate. Br J Urol 1997;79:608-610.

4. Acar C, Eskiçorapçı S, Bolat D. Prostat biyopsisi. Endoüroloji Bülteni 2010;12:16-20.

5. Nash PA, Bruce JE, Indudhara R, Shinohara K. Transrectal ultrasound guided prostatic nerve blockade eases systematic needle biopsy of the prostate. J Urol 1996;155:607-609.

6. Heidenreich A, Bastian PJ, Bellmunt J, et al. EAU guidelines on prostate cancer. part 1: screening, diagnosis, and local treatment with curative intent-update 2013. Eur Urol 2014;65:124-137.

7. Bolat $D$, Degirmenci $T$, Gunlusoy B, et al. A novel pain alternative for patients with anorectal pathologies: the comparison of transperineal prostatic blockage technique with periprostatic nerve blockage and rectal gel technique in initial transrectal ultrasound-guided prostate biopsy-a prospective, randomized trial. Urol Int 2016;97:416-420.

8. Obek C, Ozkan B, Tunc B, et al. Comparison of 3 different methods of anesthesia before transrectal prostate biopsy: a prospective randomized trial. J Urol 2004;172:502-505.

9. Djavan B, Waldert M, Zlotta A, et al. Safety and morbidity of first and repeat transrectal ultrasound guided prostate needle biopsies: results of a prospective European prostate cancer detection study. Urol 2001; 166:856-860.

10. Rodríguez LV, Terris MK. Risks and complications of transrectal ultrasound guided prostate needle biopsy: a prospective study and review of the literature. J Urol 1998;160:2115-2120.

11. Kilciler M, Demir E, Bedir S, et al. Pain scores and early complications of transrectal ultrasonography-guided prostate biopsy: effect of patient position. Urol Int 2007;79:361-363.

12. Lee $\mathrm{C}$, Woo $\mathrm{HH}$. Current methods of analgesia for transrectal ultrasonography (TRUS)-guided prostate biopsy-a systematic review. BJU Int 2014;113:48-56.

13. Luscombe CJ, Cooke PW. Pain during prostate biopsy. Lancet 2004;363:840-841.

14. Bastide C, Lechevallier E, Eghazarian C, et al. Tolerance of pain during transrectal ultrasound-guided biopsy of the prostate: risk factors. Prostate Cancer Prostatic Dis 2003;6:239-241.

15. Gómez-Gómez E, Ramírez M, Gómez-Ferrer A, et al. Assessment and clinical factors associated with pain in patients undergoing transrectal prostate biopsy. Actas Urol Esp 2015;39:414-419.

16. Moussa AS, El-Shafei A, Diaz E, et al. Identification of the variables associated with pain during transrectal ultrasonography-guided prostate biopsy in the era of periprostatic nerve block: the role of transrectal probe configuration. BJU Int 2013;111:1281-1286.

17. Bolat $D$, Aydin ME, Degirmenci T, et al. Is there a relationship between the pain scores and pathology results of transrectal-ultrasound guided prostate biopsy? Eur Urol Suppl 2016;15:1182.

18. Bolat D, Aydin ME, Degirmenci T, et al. The effect of body mass index in pain scores in patients who underwent prostate biopsy. Eur Urol Suppl 2016;15:1181. 